\title{
Teaching optics with lasers
}

\section{G. Williams, R. Zafran}

G. T. Williams, R. Zafran, "Teaching optics with lasers," Proc. SPIE 9663, Eighth International Topical Meeting on Education and Training in Optics and Photonics, 966324 (6 October 2003); doi: 10.1117/12.2208490

SPIE Event: Eighth International Topical Meeting on Education and Training in Optics and Photonics, 2003, Tucson, Arizona, United States 


\section{Teaching optics with lasers}

G.T.Williams, Physics Dept., San Jose State University, One Washington Square, San Jose, CA 95192-0106 (408) 356-9106 garethw@laserlightlab.com and $\boldsymbol{R}$. Zafran, creative science products, 650 Cayuga Dr. San Jose 95123-5506(408)972-0269vp4ever@att.net

\section{Abstract and Introduction}

The Laser Applications in Science Education and the Laser Sciences and Optics in the Classroom programs both involve hands-on teacher workshops featuring optics experiments utilizing laser pointers. This presentation describes several of these classroom-proven activities that may be easily incorporated into existing optics curricula of middle and high school science programs.

\section{Background}

The revolutionary application of lasers as an indispensable industrial tool is mirrored by their widespread usage in higher education academic
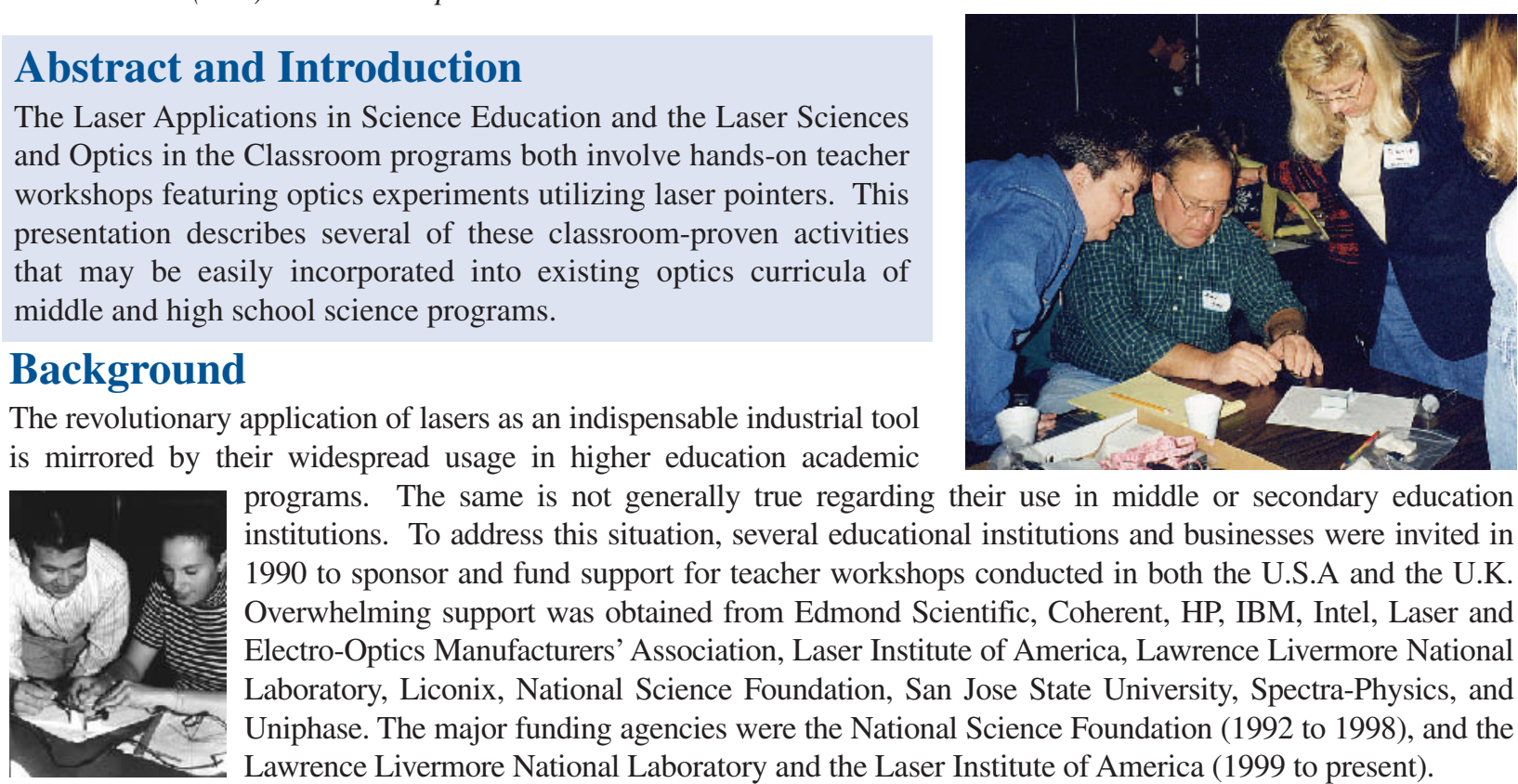

programs. The same is not generally true regarding their use in middle or secondary education institutions. To address this situation, several educational institutions and businesses were invited in 1990 to sponsor and fund support for teacher workshops conducted in both the U.S.A and the U.K. Overwhelming support was obtained from Edmond Scientific, Coherent, HP, IBM, Intel, Laser and Electro-Optics Manufacturers' Association, Laser Institute of America, Lawrence Livermore National Laboratory, Liconix, National Science Foundation, San Jose State University, Spectra-Physics, and Uniphase. The major funding agencies were the National Science Foundation (1992 to 1998), and the Lawrence Livermore National Laboratory and the Laser Institute of America (1999 to present).

\section{Laser based activities}

The following activities will be described in detail along with methods on how to achieve reliable results and also incorporate these activities with the minimum of disruption of existing curriculum.

- Laser Safety and Laser Operation

- Surveying (measurement of buildings, range finding)

- Refraction (refractive indices of liquids and concentrations)

- Fibers (numerical apertures, sensors)

- Reflection (single, double, front and back surface mirrors, reflectance measurements)

- Lenses (power, curvature of surfaces imaging)

- Detectors (construction and testing for linearity)

- Absorption (color filters, scattering media)

- Bar codes (transmission and reflection)

- Chopping (determining the speeds of motors)

- Polarization (of laser beam before and after passing through fibers, Polaroid sheets, LCDs)
- Interference (home-made double slits, interference from front and back surfaces of mirrors)

- Diffraction (CD track and diffraction grating spacing, spectra, diameter of human hairs)

- Holography (transmission and reflection holograms, holographic optical elements)

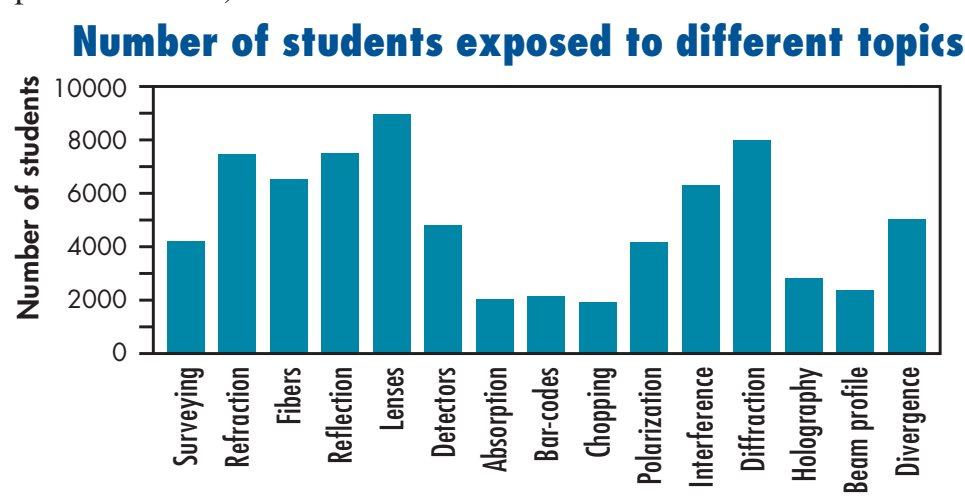

- Beam profile (divergence, diffraction, and distance measurements)

- LED's (simple voltage divider controller, use with lenses)

- Sound Transmission (transmission along a free laser beam or through a fiber)

Since 1992, a total of 35 workshops have been held throughout the USA and in the UK involving about 500 middle and high school teachers. The results of a survey illustrating teacher comfort level with the topics as well as results of student projects that were natural 'extensions' of the exciting application of lasers in their classrooms, will be presented.

Eighth International Topical Meeting on Education and Training in Optics and Photonics, edited by Barry L. Shoop, Grover Swartzlander Jr., Proc. of SPIE Vol. 9663, 966324

(C) 2003 SPIE, OSA, ICO · doi: 10.1117/12.2208490 